\title{
Comparison of calculated remnant lipoprotein cholesterol levels with levels directly measured by nuclear magnetic resonance
}

Jin Chen, Jie Kuang, Xiaoyu Tang, Ling Mao, Xin Guo, Qin Luo, Daoquan Peng and Bilian Yu* (0)

\begin{abstract}
Background: Remnant cholesterol (RC) can partly explain the residual risk in atherosclerotic cardiovascular disease (ASCVD). A consensus method of measuring RC levels has not been established yet. In clinical practice, RC levels are usually calculated from the standard lipid profile, which are not true RC. Nuclear magnetic resonance (NMR) can measure RC levels directly. This study aimed to characterize RC at fasting and non-fasting states in more details and establish the performance of calculated RC and NMR-measured RC.
\end{abstract}

Methods: Blood samples at fasting state and at $2 \mathrm{~h}$ and $4 \mathrm{~h}$ postprandial states were collected in 98 subjects. Lipid parameters including total cholesterol (TC), high-density lipoprotein cholesterol (HDL-C), low-density lipoprotein cholesterol (LDL-C), triglycerides (TG), subfractions 3, 4, and 5 of very low-density lipoprotein cholesterol $\left(V_{L D L}{ }_{3}-C_{\text {, }}\right.$ $V L D L_{4}-C$, and $V L D L_{5}-C$, respectively), and intermediate-density lipoprotein cholesterol (IDL-C) were measured by enzymatic method and NMR. RC levels calculated from the standard lipid profile or measured by NMR were referred here as $\mathrm{RCe}$ or $\mathrm{RCn}$.

Results: The RCe and RCn levels were different, but both of them increased after a meal $(P<0.05)$, especially at $4 \mathrm{~h}$ postprandial state. Low correlations were found between RCe and RCn in the 1st, 2nd, and 3rd quartiles of TG, but $\mathrm{RCn}$ showed great correlation with $\mathrm{RCe}$ in the highest quartile regardless of the fasting or non-fasting state $(R=$ $0.611,0.536$, and 0.535 for $0 \mathrm{~h}, 2 \mathrm{~h}$, and $4 \mathrm{~h}$, respectively). However, across the $2 \mathrm{nd}$ and 3 rd quartiles, RCe levels were nearly close to RCn levels. RCe levels tended to overestimate RCn levels in the 1st quartile of TGe levels with median differences of $0.23(-0.13,0.63)$ and underestimate $R C n$ levels with median differences of $-0.23(-0.33,0.07)$ in the highest quartile of TGe levels.

Conclusions: RC calculated from the standard lipid profile as TC minus LDL-C minus HDL-C is different from the NMR-measured RC. According to different TG levels, RC could overestimate or underestimate the actual RC level. Developing a consensus clinical method to measure RC levels is necessary, so that results from different studies and platforms can be more directly compared.

(Continued on next page)

\footnotetext{
* Correspondence: yubilian@csu.edu.cn

Department of Cardiovascular Medicine, the Second Xiangya Hospital, Research Institute of Blood Lipid and Atherosclerosis, Central South University, NO.139 Middle Renmin Road, Changsha 410011, Hunan, China
}

(c) The Author(s). 2020 Open Access This article is licensed under a Creative Commons Attribution 4.0 International License, which permits use, sharing, adaptation, distribution and reproduction in any medium or format, as long as you give appropriate credit to the original author(s) and the source, provide a link to the Creative Commons licence, and indicate if changes were made. The images or other third party material in this article are included in the article's Creative Commons licence, unless indicated otherwise in a credit line to the material. If material is not included in the article's Creative Commons licence and your intended use is not permitted by statutory regulation or exceeds the permitted use, you will need to obtain permission directly from the copyright holder. To view a copy of this licence, visit http://creativecommons.org/licenses/by/4.0/. The Creative Commons Public Domain Dedication waiver (http://creativecommons.org/publicdomain/zero/1.0/) applies to the data made available in this article, unless otherwise stated in a credit line to the data. 
(Continued from previous page)

Trial registration: Chinese Clinical Trial Registry, ChiCTR1900020873. Registered in 21 January 2019 - Retrospectively registered.

Keywords: Remnant cholesterol, Remnant lipoproteins, Nuclear magnetic resonance, Enzymatic method, Fasting state, Postprandial state, Residual risk, Atherosclerotic cardiovascular disease

\section{Background}

Atherosclerotic cardiovascular disease (ASCVD) is still a common cause of death worldwide $[1,2]$. Up to now, lowering plasma levels of low-density lipoprotein (LDL) cholesterol (LDL-C) is one of the primary pharmacotherapies for primary and secondary preventions of ASCVD. However, substantial residual risk remains despite achieving optimal LDL-C levels and part of this residual risk could be explained by the cholesterol content of remnant lipoproteins (RLs), known as remnant cholesterol (RC) [3-5].

Chylomicrons (CMs) and very low-density lipoproteins (VLDLs) are triglyceride (TG)-rich and metabolized into smaller and relatively cholesterol-enriched particles by lipoprotein lipase once they are in the bloodstream [6]. These partially lipolyzed particles are known as RLs including chylomicron remnants (CM-Rs), VLDL remnants (VLDL-Rs), and intermediate-density lipoproteins (IDLs). RC was defined as the cholesterol content of RLs including denser subfractions of VLDL, IDLs in the fasting state, CM-Rs in the non-fasting state, as well as the altered fasting state in individuals with hypertriglyceridemia [7, 8]. Using direct measurements, RC was estimated to account for a large proportion of total cholesterol (TC) [9]. Elevated RC has a causal association with lowgrade inflammation [10], which is related to unstable plaque and dysfunction of vascular endothelial cells. Moreover, studies have shown that high $\mathrm{RC}$ levels correlated with ischemic heart disease, high incidence of major adverse cardiovascular events, and high risk of ischemic stroke regardless of other risks $[3,4,11,12]$. In addition to fasting $\mathrm{RC}$ level, non-fasting $\mathrm{RC}$ level has a consistent association with the risk for incident coronary artery disease (CAD).

Given their diversity in structure and composition, RLs are difficult to detect and isolate [13]. The traditional method for isolating subclasses of lipoproteins is ultracentrifugation [13]. In addition, high-performance liquid chromatography and immunoseparation assays using antibodies to apolipoprotein A and apolipoprotein B can separate RLs from the plasma directly [14, 15]. These methods are undoubtedly detailed in differentiating subclasses of lipoproteins and their lipid content. However, they are cumbersome and technically demanding, which limited their clinical application. Thus, a significant challenge in studying $\mathrm{RC}$ has been the absence of a consensus assay. Past studies have used differing methods for measuring $\mathrm{RC}$, such as polyacrylamide gel electrophoresis, agarose gel electrophoresis, and vertical auto profile method, which uses ultracentrifugation with vertical rotor and single-density gradient spin [7, 8, 16-18]. In addition, Nordestgaard and Varbo $[6,19]$ pointed that the simplest way of defining $\mathrm{RC}$ is based on the cholesterol content of all TG-rich lipoproteins, that is, in the fasting state IDL and VLDL and in the non-fasting state CM-Rs. Using this definition, $\mathrm{RC}$ is the cholesterol content of all non-LDL and non-HDL and can easily be calculated from a standard lipid profile as total cholesterol (TC) minus LDL-C minus highdensity lipoprotein cholesterol (HDL-C). This method can be used without extra cost in patients anywhere if standard lipid profile data are available. However, RC from this formula contains nascent VLDL cholesterol (VLDL-C) in addition to the true $\mathrm{RC}$ in the fasting state and includes CM cholesterol in the non-fasting state [20]. Therefore, it is necessary to find the relationship between the $\mathrm{RC}$ calculated from the standard lipid profile and the true RC.

The concept of using nuclear magnetic resonance (NMR) spectroscopy in lipoprotein measurement was first introduced in the early 1990s [21]. Over the past two decades, this technique has been widely used in cardiovascular research. NMR spectroscopy can be used to explore how cholesterol is distributed in a detailed continuum of lipoprotein fractions, which allows more accurate measurement of $\mathrm{RC}[9,15,22,23]$. In addition, the NMR method is an efficient and reproducible method and has high laboratory throughput [15].

To date, only one study has compared the agreement between $\mathrm{RC}$ acquired by clinical method and RC obtained by direct measurements, except for NMR [7]. Furthermore, most of the results were based on participants who underwent an oral fat tolerance test. Consequently, finding the relationship between $\mathrm{RC}$ obtained by clinical method and that measured by NMR based on participants with conditions close to real situations is important. In this study, $\mathrm{RC}$ was calculated from the lipid profile measured by standard laboratory procedures $(\mathrm{RCe}=\mathrm{TC}-\mathrm{HDL}-\mathrm{C}-$ LDL-C) and measured by NMR $\left(\mathrm{RCn}=\mathrm{VLDL}_{3}-\mathrm{C}+\right.$ $\left.\mathrm{VLDL}_{4}-\mathrm{C}+\mathrm{VLDL}_{5}-\mathrm{C}+\mathrm{IDL}-\mathrm{C}\right)$ [7-9, 11, 24-26]. This study aimed to characterize fasting and non-fasting $\mathrm{RC}$ levels acquired by different clinical methods and to establish the performance of RCe vs RCn. 


\section{Methods}

\section{Study population}

Using data from a trial registered at Chinese Clinical Trial Registry as ChiCTR1900020873, the current study assessed the association between calculated $\mathrm{RC}$ and NMR-measured RC. Details on objectives and methodological aspects were previously reported [27]. From June 2018 to December 2018, a total of 98 subjects at the Second Xiangya Hospital of Central South University were enrolled. Briefly, all these subjects underwent detailed clinical, laboratory, and angiographic examinations, and they were divided into the CAD group and the non-CAD group. The diagnosis of CAD was based on electrocardiographic changes, serum troponin $\mathrm{T}$, and coronary angiography showing $\geq 50 \%$ stenosis in at least one main coronary artery. Non-CAD controls were recruited on the same period but free from atherosclerotic disorders as confirmed by coronary angiography or coronary computed tomography angiography. Besides, patients with significant hematologic disorders, infectious or inflammatory disease, various tumors, severe liver and/ or renal insufficiency, severe uncontrolled diabetes or hypertension, and alcohol use or intensive exercise in the week before enrollment were excluded.

The study was approved by the Medical Ethics Committee of the Second Xiangya Hospital of Central South University (SXHCSU2019049). Informed consents were obtained from all subjects.

\section{Blood sample collection and lipid measurements}

The blood sample collection method has been described previously [27]. Briefly, after overnight fasting for at least $10 \mathrm{~h}$, all participants were allowed to have breakfast as usual. Chinese breakfast usually consists of steamed buns, noodles, eggs, milk, and soups with a bit of oil, and the energy content might be $500-600 \mathrm{kcal}$ with $8-$ $10 \%$ fat. The kinds of food and beverages consumed, the time of intake, quantities consumed in portion sizes, and preparation forms were recorded. Peripheral venous blood at the fasting state and at $2 \mathrm{~h}$ and $4 \mathrm{~h}$ postprandial states was collected. Blood samples were centrifuged immediately and analyzed or stored at $-80^{\circ} \mathrm{C}$ for future analyses.

Blood lipids and lipoproteins were detected in two ways. First, the levels of plasma TC, HDL-C, LDL-C, and TG (TCe, HDL-Ce, LDL-Ce, and TGe, respectively) were measured by enzymatic measures using Roche automated clinical chemistry analyzer. Second, plasma TC, HDL-C, LDL-C, TG, VLDL3-C, VLDL4-C, VLDL5$\mathrm{C}$, and IDL-C levels (TCn, HDL-Cn, LDL-Cn, TGn, VLDL3-C, VLDL4-C, VLDL5-C, and IDL-C, respectively) were measured at ProteinT Biotechnology Co., Ltd. (Tianjin, China) using Bruker $600 \mathrm{MHz}$ Avance III NMR spectrometer as previously described [27, 28].
Details for the NMR experimental condition are provided in Additional File 1: Table S1. The spectra were normalized to the same quantitative scale using Bruker's QuantRef manager within TopSpin which is based on the PULCON method; hence, the spectral intensity is normalized to proton concentration in units of millimoles per liter [29]. For data analysis, the study selected the commercial Bruker IVDr LIpoprotein Subclass Analysis (B.I.-LISA) method [28, 30] as lipoprotein distribution prediction method, which used a PLS-2 regression model as the algorithm for spectral deconvolution [31]. The PLS-2 model was built using bucketing parameters (size, number, and exclusions) similar way to those used by Okazaki et al. [31]. The lipoprotein subclass data available have five different VLDL subclasses: VLDL1 (average particle diameter of $64.0 \mathrm{~nm})$, VLDL2 (53.6 $\mathrm{nm})$, VLDL3 (44.5 nm), VLDL4 (36.8 nm), VLDL5 (31.3 $\mathrm{nm})$, and IDL (28.6 $\mathrm{nm})$ [32].

\section{Calculation of RC}

The actual RC was defined as the sum of the cholesterol contents of the denser subfractions of VLDL and IDLs in the fasting state and CM-Rs in the non-fasting state. As described previously, VLDL can be identified into five subclasses by using NMR, namely, $\mathrm{VLDL}_{1}$ and $\mathrm{VLDL}_{2}$ as the large and buoyant TG-rich subclasses and $\mathrm{VLDL}_{3-5}$ as relatively cholesterol-rich small and dense subclasses [9, 24-26]. CM-Rs cannot be differentiated by NMR, and CM-Rs could be included in VLDL-Rs or even in IDLs, depending on their size $[7,9,33]$. Thus, the equation to calculate the actual $\mathrm{RC}$ by NMR (RCn) is as follows: $\mathrm{VLDL}_{3}-\mathrm{C}+\mathrm{VLDL}_{4}-\mathrm{C}+$ $\mathrm{VLDL}_{5}-\mathrm{C}+\mathrm{IDL}-\mathrm{C}$. In addition, in clinical practice, the estimated $\mathrm{RC}$ is calculated as follows: TC - HDL-C - directly measured LDL-C $[7,34]$. Thus, in this study, another equation to calculate RC (RCe) is TCe - (HDL-Ce + LDL-Ce), which is calculated from the standard lipid profile measured by Roche automated clinical chemistry analyzers.

\section{Statistical analysis}

All statistical data were analyzed by SPSS 25.0 (IBM Corp., Armonk, NY, USA) and Graph Pad Prism 7.0 software (GraphPad Software Inc., La Jolla, CA). Continuous variables approximating a normal distribution were reported as mean \pm standard deviation (SD), and their differences were assessed by either Student's t-test or analysis of variance methods. Continuous variables deviating from a normal distribution were reported as medians (25th-75th percentile) with differences compared by the Mann-Whitney U-test, Kruskal-Wallis test, or Wilcoxon signed rank test. Besides, categorical variables were expressed as count (\%) and compared by $\chi^{2}$ test or Fisher's exact test. The relationships among RC and other lipid parameters were assessed using Spearman's correlations analysis. 
In addition, the within-subject differences between $\mathrm{RCe}$ and $\mathrm{RCn}$ were calculated using the equation $(\mathrm{RCe}-\mathrm{RCn})$ / (RCn) [7]. Positive values represent overestimation of $\mathrm{RCn}$ by RCe, whereas negative values represent underestimation. Moreover, these differences within groups stratified by TG quartiles at different times and Spearman's correlations between RCe and RCn in different TG quartiles were compared. An association between CAD and its risk factors was determined by logistic regression analysis. Two-tailed $P$ values $<0.05$ were considered statistically significant.

\section{Results}

\section{Baseline characteristics}

The baseline characteristics of the study population are illustrated in Table 1. The participants consist of 57 men (58\%) and 41 women (42\%), aged 38-66 years. As the chart shows, the CAD group was significantly older than the non-CAD group. The frequencies of other conventional risk factors such as male sex, hypertension, diabetes, and smoking habits were significantly higher in the $\mathrm{CAD}$ group than in the non-CAD group. In addition, baseline lipids were significantly different between the two groups; notable differences included much higher TGe, lower TCe and LDL-Ce, and higher HDL-Ce in the CAD group, and the lower LDL-Ce could be associated with the higher percentage of statin treatment in the CAD group. In terms of $\mathrm{RC}$, the RCe level was slightly higher in the CAD group than in the non-CAD group [22.20(17.86, 28.67) $\mathrm{mg} / \mathrm{dL}$ vs $18.15(14.19,22.48) \mathrm{mg} / \mathrm{dL}$,
$P=0.003]$, and no significant differences were found in the RCn levels between the two groups.

NMR-measured baseline lipids showed significant positive correlations with those measured by enzymatic method

The correlations between lipid parameters measured by NMR and enzymatic method are shown in Table 2. By incorporating the data of all subjects into the statistical analysis, regardless of whether subjects are in the fasting or postprandial state, levels of plasma TGn were strongly correlated with TGe levels as expected $(\mathrm{R}=0.979,0.967$, and 0.978 for $0 \mathrm{~h}, 2 \mathrm{~h}$, and $4 \mathrm{~h}$, respectively). Although the correlation value between $\mathrm{TCn}$ and $\mathrm{TCe}$ was $>0.9$, LDL-Cn had a weaker correlation with LDL-Ce $(\mathrm{R}=$ $0.765,0.777$, and 0.744 for $0 \mathrm{~h}, 2 \mathrm{~h}$, and $4 \mathrm{~h}$, respectively). Notably, regardless of the fasting or postprandial state, the LDL-Cn levels were lower than the LDL-Ce levels (Fig. 1). To exclude the influence of IDL-C, it was necessary to compare LDL-Ce levels and the sum of IDL-C and LDL-Cn levels. Obviously, the sum of LDL-Cn and IDL-C levels were also lower than the LDL-Ce levels in fasting and $2 \mathrm{~h}$ postprandial states $(P<0.05)$.

\section{Postprandial changes in blood lipids}

In $\mathrm{CAD}$ or non-CAD participants, plasma TGe levels were significantly elevated after a meal as expected (Fig. 2a). Consistent with the previous reports [27], the levels of TCe, HDL-Ce, and LDL-Ce decreased significantly in the $2 \mathrm{~h}$ postprandial period. The $4 \mathrm{~h}$ postprandial TCe and HDL-Ce levels were nearly equal to their

Table 1 Baseline characteristics and lipoprotein summaries

\begin{tabular}{|c|c|c|c|c|}
\hline \multirow[t]{2}{*}{ Variable } & \multirow{2}{*}{$\begin{array}{l}\text { All } \\
(n=98)\end{array}$} & \multicolumn{2}{|l|}{ Coronary artery disease } & \multirow[t]{2}{*}{$P$ value } \\
\hline & & $\operatorname{Yes}(n=36)$ & $\mathrm{No}(n=62)$ & \\
\hline Age (years) & $52 \pm 14$ & $61 \pm 8$ & $47 \pm 14$ & $<0.001{ }^{*} \mathrm{~b}$ \\
\hline Men & $57(58 \%)$ & 29 (81\%) & $28(45 \%)$ & $0.001^{* a}$ \\
\hline Hypertension & $33(34 \%)$ & $18(50 \%)$ & $15(24 \%)$ & $0.009^{*} a$ \\
\hline Diabetes & $14(14 \%)$ & 12 (33\%) & $2(3 \%)$ & $<0.001^{*} \mathrm{a}$ \\
\hline Smoking & $25(26 \%)$ & $14(39 \%)$ & $11(18 \%)$ & $0.021^{* a}$ \\
\hline $\mathrm{BMI}(\mathrm{kg} / \mathrm{m} 2)$ & $24 \pm 4$ & $25 \pm 3$ & $24 \pm 4$ & $0.605^{b}$ \\
\hline $\mathrm{TC}(\mathrm{mg} / \mathrm{dL})$ & $162.02 \pm 35.13$ & $147.32 \pm 36.34$ & $170.55 \pm 31.67$ & $0.001^{*} \mathrm{~b}$ \\
\hline $\mathrm{LDL}-\mathrm{C}(\mathrm{mg} / \mathrm{dL})$ & $98.84(77.99,120.46)$ & $79.15(69.98,111.58)$ & $102.70(89.38,122.30)$ & $0.003^{*} c$ \\
\hline $\mathrm{HDL}-\mathrm{C}(\mathrm{mg} / \mathrm{dL})$ & $41.62 \pm 10.70$ & $45.22 \pm 10.23$ & $35.42 \pm 8.53$ & $<0.001^{*}$ b \\
\hline $\mathrm{TG}(\mathrm{mg} / \mathrm{dL})$ & $130.97(93.58,198.23)$ & $166.37(105.53,238.94)$ & $120.35(91.59,178.10)$ & $0.047^{*} \subset$ \\
\hline $\mathrm{RCe}(\mathrm{mg} / \mathrm{dL})$ & $19.13(15.35,24.32)$ & $22.20(17.86,28.67)$ & $18.15(14.19,22.48)$ & $0.003^{*} c$ \\
\hline $\mathrm{RCn}(\mathrm{mg} / \mathrm{dL})$ & $21.51(13.96,30.51)$ & $21.09(14.10,28.91)$ & $21.51(13.81,35.66)$ & $0.517^{c}$ \\
\hline
\end{tabular}

Values are mean $\pm S D, n \%$, or median (25th percentile, 75 th percentile)

$B M I$ Body mass index, TG Triglycerides, TC Total cholesterol, HDL-C High density lipoprotein cholesterol, $L D L-C$ Low-density lipoprotein cholesterol, $R C$ Remnant cholesterol

$\mathrm{RCn}=\mathrm{VLDL}_{3}-\mathrm{C}+\mathrm{VLDL}_{4}-\mathrm{C}+\mathrm{VLDL}_{5}-\mathrm{C}+\mathrm{IDL}-\mathrm{C} ; \mathrm{RCe}=\mathrm{TCe}$ minus (HDL-Ce $+\mathrm{LDL}-\mathrm{Ce}$ )

${ }^{a} X^{2}$ test or Fisher's exact test

b Student's T test

c Mann-Whitney U-test

* P-value < 0.05 
Table 2 Spearman's correlation coefficients between lipids measured by enzymatic method or NMR

\begin{tabular}{|c|c|c|c|}
\hline & Spearman $\mathrm{R}$ ( $P$ value) & Slope & Intercept \\
\hline \multicolumn{4}{|c|}{ TGn vs TGe $(n=98)$} \\
\hline Fasting & $0.979\left(<0.001{ }^{*}\right)$ & $1.11 \pm 0.02$ & $-0.43 \pm 2.90$ \\
\hline $2 \mathrm{~h}$ Postprandial & $0.967\left(<0.0011^{*}\right)$ & $1.13 \pm 0.02$ & $2.05 \pm 4.90$ \\
\hline 4h Postprandial & $0.978\left(<0.001^{*}\right)$ & $1.17 \pm 0.03$ & $-7.75 \pm 5.83$ \\
\hline \multicolumn{4}{|l|}{$\operatorname{TCn}$ vs $\operatorname{TCe}(n=98)$} \\
\hline Fasting & $0.949\left(<0.001^{*}\right)$ & $0.94 \pm 0.03$ & $-0.06 \pm 5.17$ \\
\hline $2 \mathrm{~h}$ Postprandial & $0.934\left(<0.001{ }^{*}\right)$ & $0.80 \pm 0.03$ & $17.31 \pm 6.20$ \\
\hline 4h Postprandial & $0.937\left(<0.001^{*}\right)$ & $0.84 \pm 0.03$ & $10.61 \pm 5.26$ \\
\hline \multicolumn{4}{|c|}{ HDL-Cn vs HDL-Ce $(n=98)$} \\
\hline Fasting & $0.858\left(<0.001^{*}\right)$ & $1.04 \pm 0.05$ & $-9.37 \pm 2.56$ \\
\hline $2 \mathrm{~h}$ Postprandial & $0.788\left(<0.001^{*}\right)$ & $0.91 \pm 0.06$ & $-4.71 \pm 3.04$ \\
\hline $4 \mathrm{~h}$ Postprandial & $0.700\left(<0.001^{*}\right)$ & $0.84 \pm 0.07$ & $1.16 \pm 3.73$ \\
\hline \multicolumn{4}{|c|}{ LDL-Cn vs LDL-Ce $(n=98)$} \\
\hline Fasting & $0.765\left(<0.001^{*}\right)$ & $0.85 \pm 0.07$ & $31.93 \pm 5.95$ \\
\hline $2 \mathrm{~h}$ Postprandial & $0.777\left(<0.001^{*}\right)$ & $0.96 \pm 0.07$ & $18.83 \pm 6.35$ \\
\hline 4h Postprandial & $0.744\left(<0.001^{*}\right)$ & $0.79 \pm 0.07$ & $27.79 \pm 6.11$ \\
\hline \multicolumn{4}{|c|}{ RCn vs RCe $(n=98)$} \\
\hline Fasting & $0.586\left(<0.001{ }^{*}\right)$ & $0.45 \pm 0.05$ & $9.72 \pm 1.39$ \\
\hline $2 \mathrm{~h}$ Postprandial & $0.534\left(<0.001^{*}\right)$ & $0.46 \pm 0.06$ & $11.70 \pm 1.66$ \\
\hline $4 \mathrm{~h}$ Postprandial & $0.653\left(<0.001^{*}\right)$ & $0.98 \pm 0.10$ & $0.73 \pm 2.97$ \\
\hline
\end{tabular}

Values are mean \pm SD

*Indicates statistical significance $P<0.05$

levels in the fasting state, while LDL-Ce levels were still decreased (Fig. 2 b-d). Similarly, the downward trends were seen in the TCn, HDL-Cn, and LDL-Cn levels in CAD patients after a meal. It appears that TCn, HDL$\mathrm{Cn}$, and LDL-Cn levels are increased in the $2 \mathrm{~h}$ postprandial state for non-CAD patients, but no statistical significance exists (Fig. 2 e-h).
Except for the slight decrease in RCn levels in CAD patients, regardless of dividing the subjects into the CAD group and non-CAD group, both $\mathrm{RCe}$ and $\mathrm{RCn}$ levels showed an upward trend after a typical breakfast (Fig. 3). Although the levels of TCe, HDL-Ce, and LDLCe decreased in the $2 \mathrm{~h}$ postprandial period, the total decrease in LDL-Ce and HDL-Ce levels was greater than that of the TC level $(5.02(-1.16,11.58)$ vs $4.05(-5.21$, 9.65), $P<0.05)$, which could explain the increase in the calculated RCe level after a meal.

\section{Comparing different assessments of RC in the fasting and} postprandial states

The correlations between RC and TG were first analyzed. As shown in Table 3, RCn and RCe both showed strong positive correlations with TG, and the correlation values between $\mathrm{RCn}$ and TGn were 0.847 for fasting and 0.765 and 0.827 for postprandial $2 \mathrm{~h}$ and $4 \mathrm{~h}$, respectively, whereas the correlation values between $\mathrm{RCe}$ and TGe were 0.615 for fasting and 0.534 and 0.753 for postprandial $2 \mathrm{~h}$ and $4 \mathrm{~h}$, respectively. RCn was strongly correlated with VLDL3-C, VLDL4-C, and IDL-C levels (fasting $\mathrm{R}=0.899,0.931$, and $0.966 ; 2 \mathrm{~h}$ postprandial $\mathrm{R}=$ $0.853,0.895,0.969 ; 4 \mathrm{~h}$ postprandial $\mathrm{R}=0.865,0.883$, and 0.962 , respectively; Table 3). The concordance between RCe and VLDL3-C, VLDL4-C, or IDL-C was weaker (fasting $\mathrm{R}=0.550,0.501$, and $0.579 ; 2 \mathrm{~h}$ postprandial $\mathrm{R}=$ $0.437,0.425$, and $0.531 ; 4$ h postprandial $R=0.554,0.502$, and 0.658 , respectively). However, VLDL5-C was weakly correlated with $\mathrm{RCn}(\mathrm{R}=0.435,0.378$, and 0.168 for $0 \mathrm{~h}$, $2 \mathrm{~h}$, and $4 \mathrm{~h}$, respectively), even less so with $\mathrm{RCe}(\mathrm{R}=$ $0.262,0.221$, and 0.057 for $0 \mathrm{~h}, 2 \mathrm{~h}$, and $4 \mathrm{~h}$, respectively). Moreover, although the calculation methods of the RCn and RCe were different, $\mathrm{RCn}$ still showed positive correlation with $\mathrm{RCe}$ at the fasting state $(\mathrm{R}=0.586, P<0.001$, Table 2), and their correlation was slightly stronger after a meal $(\mathrm{R}=0.653$ for $4 \mathrm{~h}$ postprandial, $P<0.001)$.
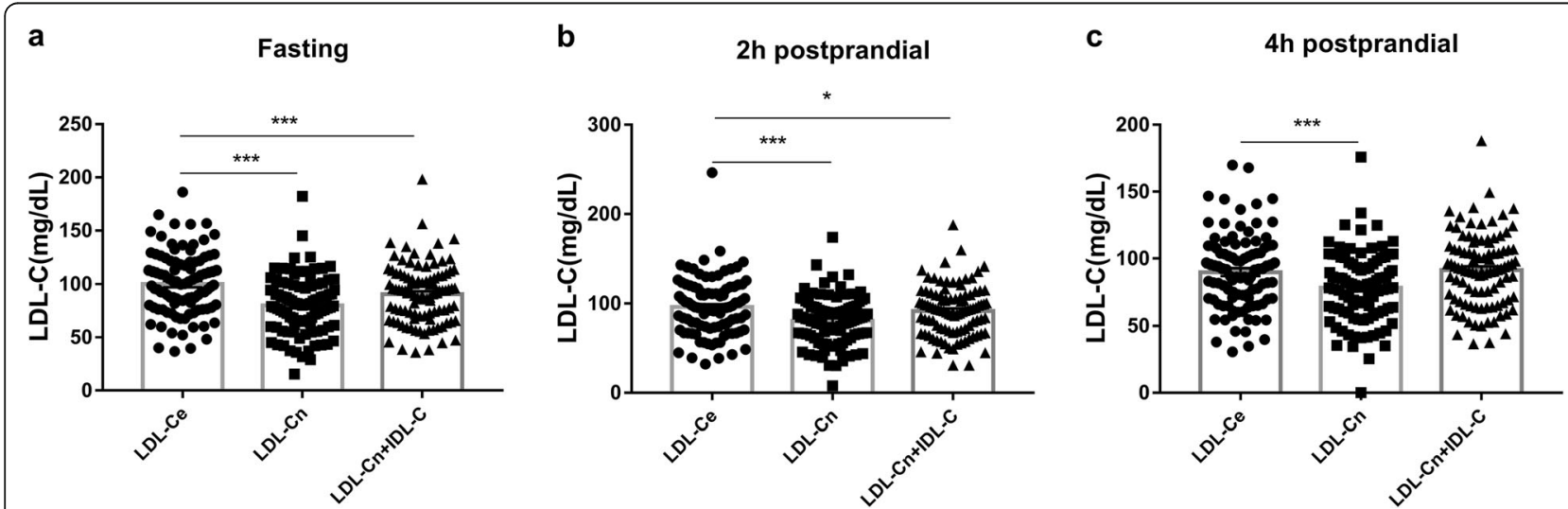

Fig. 1 Comparisons between LDL-Ce levels and LDL-Cn levels or the sum levels of $L D L-C n$ and IDL-C. The sum levels of $L D L-C n$ and IDL-C $=L D L-C n+$ IDL-C; Fasting state(a), $2 \mathrm{~h}$ postprandial state $(\mathbf{b}), 4 \mathrm{~h}$ postprandial state $(\mathbf{c}) .{ }^{* * *}$ means $P$ value $<0.001 ;{ }^{* *}$ means $P$ value $<0.01 ;{ }^{*}$ means $P$ value $<0.05$ 


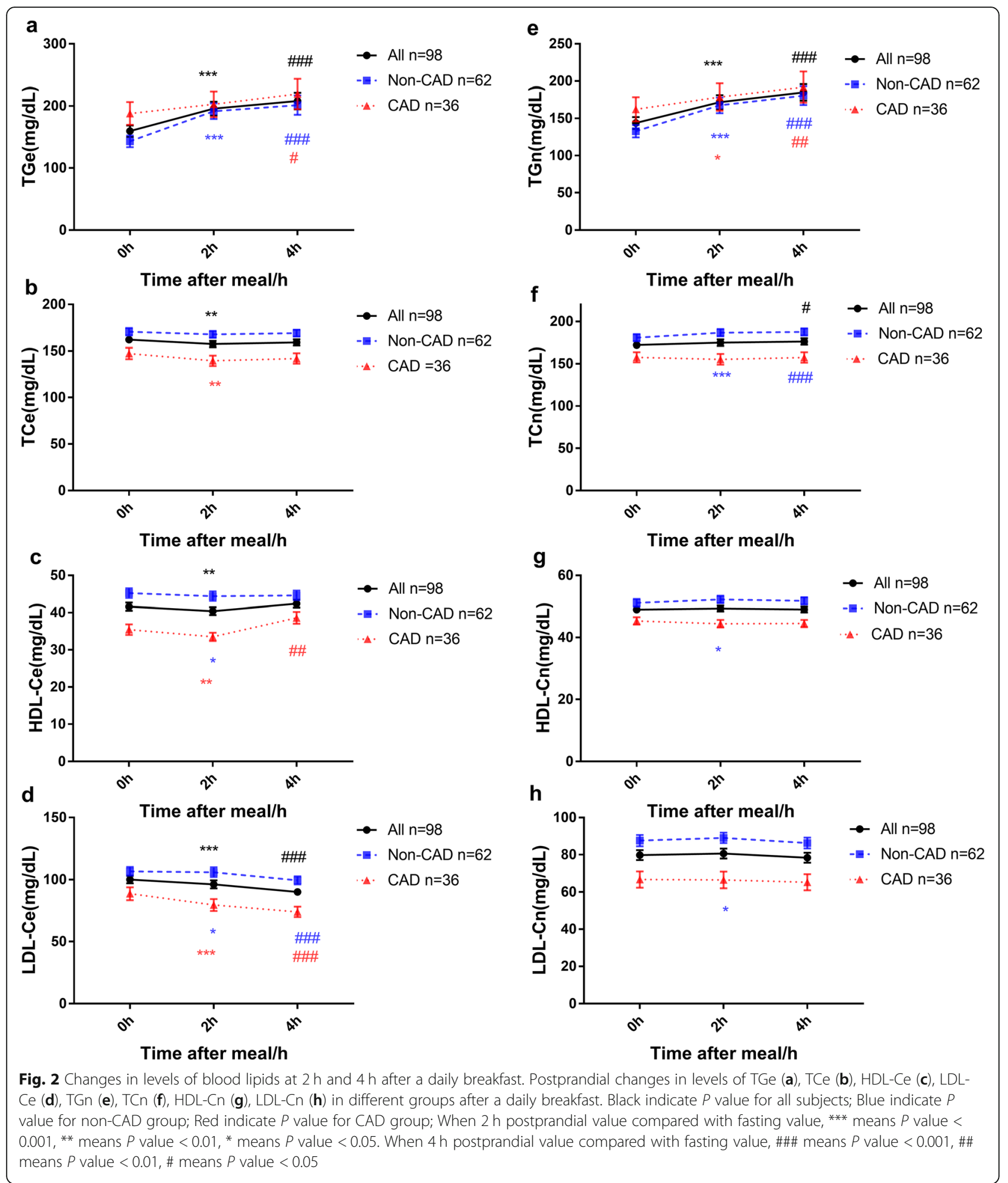

To further investigate the relationship between $\mathrm{RCe}$ and $\mathrm{RCn}$, this study analyzed the correlations between $\mathrm{RCn}$ and RCe stratified by TG quartiles at different time in all subjects. As shown in Table 4, low correlations were found between
RCe and RCn in the 1st, 2nd, and 3rd quartiles of TGe, but $\mathrm{RCn}$ showed great correlations with RCe in the highest quartile regardless of the fasting or non-fasting state $(R=0.611$, 0.536 , and 0.535 for $0 \mathrm{~h}, 2 \mathrm{~h}$, and $4 \mathrm{~h}$, respectively, Table 4 ). 

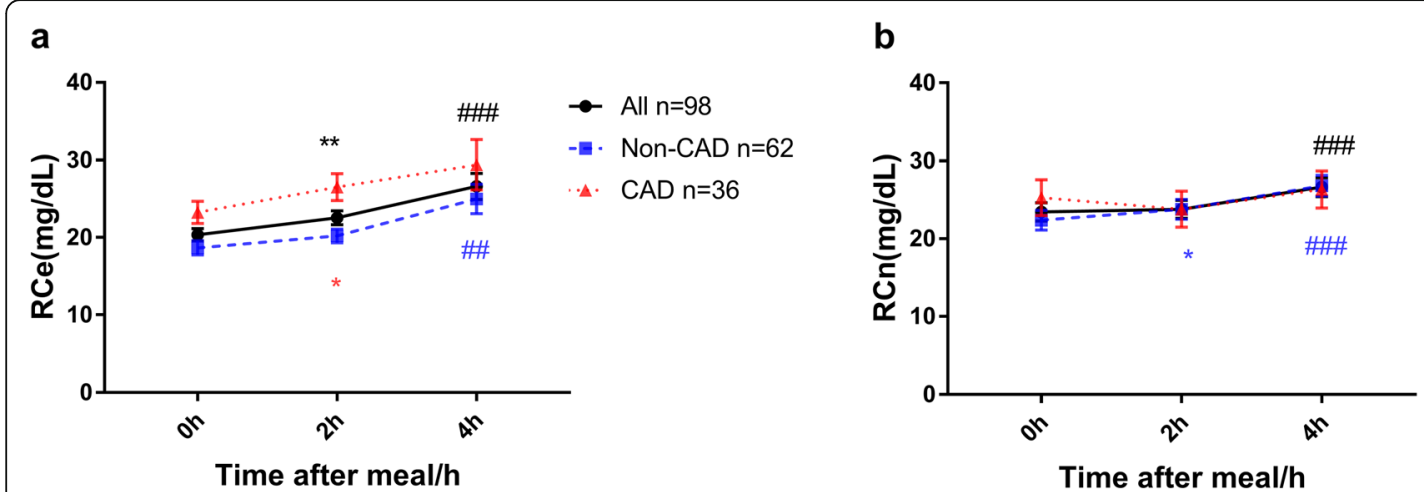

Fig. 3 Changes in levels of RCe and RCn at $2 \mathrm{~h}$ and $4 \mathrm{~h}$ after a daily breakfast. Postprandial changes in levels of RCe (a), RCn (b), in different groups after a daily breakfast; Black indicate $P$ value for all subjects; Blue indicate $P$ value for non-CAD group; Red indicate $P$ value for CAD group; When $2 \mathrm{~h}$ postprandial value compared with fasting value, ${ }^{* * *}$ means $P$ value $<0.001$, ${ }^{* *}$ means $P$ value $<0.01,{ }^{*}$ means $P$ value $<0.05$. When $4 \mathrm{~h}$ postprandial value compared with fasting value, \#\# means $P$ value $<0.001$, \#\# means $P$ value $<0.01$, \# means $P$ value $<0.05$

Moreover, considering that $198.23 \mathrm{mg} / \mathrm{dL}$ might be a high cutoff value, which could bias the results, this study divided all subjects into two groups based on the normal value of the fasting TGe level: TGe-low group with $<150$ $\mathrm{mg} / \mathrm{dL}$ and TGe-high group with $\geq 150 \mathrm{mg} / \mathrm{dL}$. Obviously, the ability for RCe levels to predict RCn levels was consistent with prior analysis, and significant correlations still exists between RCe and RCn in the TGe-high group; especially, their correlations were slightly stronger after a meal $(\mathrm{R}=0.475,0.527$, and 0.567 for $0 \mathrm{~h}, 2 \mathrm{~h}$, and $4 \mathrm{~h}$, respectively; Table 5), but low correlations were found between $\mathrm{RCe}$ and $\mathrm{RCn}$ in the TGe-low group.

To explore whether there is an exact TG cutoff value in which RCn levels are equal to RCe levels, the study

Table 3 Spearman's correlation coefficients between RC and other lipids parameters $(n=98)$

\begin{tabular}{|c|c|c|c|c|c|c|}
\hline & \multicolumn{2}{|c|}{$\begin{array}{l}\text { Fasting Spearman } \\
\mathrm{R}(P \text { value })\end{array}$} & \multicolumn{2}{|c|}{$\begin{array}{l}2 \mathrm{~h} \text { postprandial } \\
\text { Spearman } \mathrm{R} \text { ( } P \text { value) }\end{array}$} & \multicolumn{2}{|c|}{$\begin{array}{l}4 \mathrm{~h} \text { postprandial } \\
\text { Spearman } \mathrm{R} \text { ( } P \text { value) }\end{array}$} \\
\hline & $\overline{\mathrm{RCe}}$ & $\mathrm{RCn}$ & $\overline{\mathrm{RCe}}$ & $\mathrm{RCn}$ & $\overline{\mathrm{RCe}}$ & $\mathrm{RCn}$ \\
\hline$\overline{\mathrm{TGe}}$ & $\begin{array}{l}0.615 \\
\left(<0.001^{*}\right)\end{array}$ & $\begin{array}{l}0.848 \\
\left(<0.001^{*}\right)\end{array}$ & $\begin{array}{l}0.534 \\
\left(<0.001^{*}\right)\end{array}$ & $\begin{array}{l}0.759 \\
\left(<0.001^{*}\right)\end{array}$ & $\begin{array}{l}0.753 \\
\left(<0.001^{*}\right)\end{array}$ & $\begin{array}{l}0.801 \\
\left(<0.001^{*}\right)\end{array}$ \\
\hline TGn & $\begin{array}{l}0.617 \\
\left(<0.001^{*}\right)\end{array}$ & $\begin{array}{l}0.847 \\
\left(<0.001^{*}\right)\end{array}$ & $\begin{array}{l}0.513 \\
\left(<0.001^{*}\right)\end{array}$ & $\begin{array}{l}0.765 \\
\left(<0.001^{*}\right)\end{array}$ & $\begin{array}{l}0.718 \\
\left(<0.001^{*}\right)\end{array}$ & $\begin{array}{l}0.827 \\
\left(<0.001^{*}\right)\end{array}$ \\
\hline $\mathrm{TCe}$ & $\begin{array}{l}0.364 \\
\left(<0.001^{*}\right)\end{array}$ & $\begin{array}{l}0.536 \\
\left(<0.001^{*}\right)\end{array}$ & $\begin{array}{l}0.326 \\
\left(<0.001^{*}\right)\end{array}$ & $\begin{array}{l}0.652 \\
\left(<0.001^{*}\right)\end{array}$ & $\begin{array}{l}0.431 \\
\left(<0.001^{*}\right)\end{array}$ & $\begin{array}{l}0.651 \\
\left(<0.001^{*}\right)\end{array}$ \\
\hline $\mathrm{TCn}$ & $\begin{array}{l}0.349 \\
\left(<0.001^{*}\right)\end{array}$ & $\begin{array}{l}0.582 \\
\left(<0.001^{*}\right)\end{array}$ & $\begin{array}{l}0.335 \\
\left(0.001^{*}\right)\end{array}$ & $\begin{array}{l}0.690 \\
\left(<0.001^{*}\right)\end{array}$ & $\begin{array}{l}0.501 \\
\left(<0.001^{*}\right)\end{array}$ & $\begin{array}{l}0.717 \\
\left(<0.001^{*}\right)\end{array}$ \\
\hline HDL-Ce & $\begin{array}{l}-0.270 \\
\left(0.007^{*}\right)\end{array}$ & $\begin{array}{l}-0.296 \\
\left(0.003^{*}\right)\end{array}$ & $\begin{array}{l}-0.266 \\
\left(0.008^{*}\right)\end{array}$ & $\begin{array}{l}-0.136 \\
(0.181)\end{array}$ & $\begin{array}{l}-0.267 \\
\left(0.008^{*}\right)\end{array}$ & $\begin{array}{l}-0.241 \\
\left(0.017^{*}\right)\end{array}$ \\
\hline $\mathrm{HDL}-\mathrm{Cn}$ & $\begin{array}{l}-0.141 \\
(0.166)\end{array}$ & $\begin{array}{l}-0.235 \\
\left(0.019^{*}\right)\end{array}$ & $\begin{array}{l}0.024 \\
(0.817)\end{array}$ & $\begin{array}{l}0.045 \\
(0.660)\end{array}$ & $\begin{array}{l}0.014 \\
(0.892)\end{array}$ & $\begin{array}{l}-0.006 \\
(0.952)\end{array}$ \\
\hline LDL-Ce & $\begin{array}{l}0.278 \\
\left(0.006^{*}\right)\end{array}$ & $\begin{array}{l}0.588 \\
\left(<0.001^{*}\right)\end{array}$ & $\begin{array}{l}0.196 \\
(0.055)\end{array}$ & $\begin{array}{l}0.647 \\
\left(<0.001^{*}\right)\end{array}$ & $\begin{array}{l}0.117 \\
(0.253)\end{array}$ & $\begin{array}{l}0.504 \\
\left(<0.001^{*}\right)\end{array}$ \\
\hline LDL-Cn & $\begin{array}{l}0.002 \\
(0.986)\end{array}$ & $\begin{array}{l}0.099 \\
(0.330)\end{array}$ & $\begin{array}{l}0.044 \\
(0.672)\end{array}$ & $\begin{array}{l}0.234 \\
\left(0.020^{*}\right)\end{array}$ & $\begin{array}{l}0.073 \\
(0.475)\end{array}$ & $\begin{array}{l}0.189 \\
(0.062)\end{array}$ \\
\hline VLDL3-C & $\begin{array}{l}0.550 \\
\left(<0.001^{*}\right)\end{array}$ & $\begin{array}{l}0.899 \\
\left(<0.001^{*}\right)\end{array}$ & $\begin{array}{l}0.437 \\
\left(<0.001^{*}\right)\end{array}$ & $\begin{array}{l}0.853 \\
\left(<0.001^{*}\right)\end{array}$ & $\begin{array}{l}0.544 \\
\left(<0.001^{*}\right)\end{array}$ & $\begin{array}{l}0.865 \\
\left(<0.001^{*}\right)\end{array}$ \\
\hline VLDL4-C & $\begin{array}{l}0.501 \\
\left(<0.001^{*}\right)\end{array}$ & $\begin{array}{l}0.931 \\
\left(<0.001^{*}\right)\end{array}$ & $\begin{array}{l}0.425 \\
\left(<0.001^{*}\right)\end{array}$ & $\begin{array}{l}0.895 \\
\left(<0.001^{*}\right)\end{array}$ & $\begin{array}{l}0.502 \\
\left(<0.001^{*}\right)\end{array}$ & $\begin{array}{l}0.883 \\
\left(<0.001^{*}\right)\end{array}$ \\
\hline VLDL5-C & $\begin{array}{l}0.262 \\
\left(0.009^{*}\right)\end{array}$ & $\begin{array}{l}0.435 \\
\left(<0.001^{*}\right)\end{array}$ & $\begin{array}{l}0.221 \\
\left(0.029^{*}\right)\end{array}$ & $\begin{array}{l}0.378 \\
\left(<0.001^{*}\right)\end{array}$ & $\begin{array}{l}0.057 \\
(0.580)\end{array}$ & $\begin{array}{l}0.168 \\
(0.098)\end{array}$ \\
\hline $\mathrm{IDL}-\mathrm{C}$ & $\begin{array}{l}0.579 \\
\left(<0.001^{*}\right)\end{array}$ & $\begin{array}{l}0.966 \\
\left(<0.001^{*}\right)\end{array}$ & $\begin{array}{l}0.531 \\
\left(<0.001^{*}\right)\end{array}$ & $\begin{array}{l}0.969 \\
\left(<0.001^{*}\right)\end{array}$ & $\begin{array}{l}0.658 \\
\left(<0.001^{*}\right)\end{array}$ & $\begin{array}{l}0.962 \\
\left(<0.001^{*}\right)\end{array}$ \\
\hline
\end{tabular}

$V L D L_{3}-C$ subfraction 3 of very low-density lipoprotein cholesterol, $V L D L_{4}-C$ subfraction 4 of very low-density lipoprotein cholesterol, $V L D L_{5}-C$ subfraction 5 of very low-density lipoprotein cholesterol, IDL-C Intermediate-density lipoprotein cholesterol

*Indicates statistical significance $P<0.05$ 
Table 4 The Spearman's correlations between RCe and RCn according to the TGe quartiles

\begin{tabular}{|c|c|c|c|c|}
\hline & Quartile 1 & Quartile 2 & Quartile 3 & Quartile 4 \\
\hline Fasting $(n=98)$ & {$[54.87,93.58]$} & $(93.58,130.97]$ & $(130.97,198.23]$ & $(198.23,426.55]$ \\
\hline Spearman $\mathrm{R}$ ( $P$ value) & $0.066(0.760)$ & $0.319(0.120)$ & $0.207(0.320)$ & $0.611\left(0.002^{*}\right)$ \\
\hline Slope & $-0.08 \pm 0.24$ & $0.27 \pm 0.18$ & $0.27 \pm 0.16$ & $0.56 \pm 0.16$ \\
\hline Intercept & $17.06 \pm 3.03$ & $10.41 \pm 3.68$ & $15.49 \pm 4.26$ & $6.21 \pm 6.05$ \\
\hline $2 \mathrm{~h}$ Postprandial $(n=98)$ & {$[46.02,110.40]$} & $(110.40,173.01]$ & $(173.01,258.19]$ & $(258.19,606.19]$ \\
\hline Spearman $\mathrm{R}$ ( $P$ value) & $-0.025(0.970)$ & $-0.083(0.669)$ & $0.280(0.175)$ & $0.536\left(0.007^{*}\right)$ \\
\hline Slope & $-0.03 \pm 0.19$ & $0.11 \pm 0.17$ & $0.28 \pm 0.20$ & $0.63 \pm 0.18$ \\
\hline Intercept & $17.22 \pm 2.87$ & $18.85 \pm 3.49$ & $16.00 \pm 5.08$ & $5.97 \pm 6.98$ \\
\hline $4 \mathrm{~h}$ Postprandial $(n=98)$ & {$[44.25,110.40]$} & $(110.40,168.14]$ & $(168.14,269.69]$ & $(269.69,694.69]$ \\
\hline Spearman $\mathrm{R}$ ( $P$ value) & $0.087(0.693)$ & $0.056(0.790)$ & $0.234(0.260)$ & $0.535\left(0.007^{*}\right)$ \\
\hline Slope & $0.09 \pm 0.21$ & $0.07 \pm 0.22$ & $0.19 \pm 0.24$ & $1.15 \pm 0.42$ \\
\hline Intercept & $14.22 \pm 3.45$ & $17.80 \pm 4.68$ & $21.50 \pm 6.57$ & $-3.50 \pm 18.40$ \\
\hline All statistics $(n=294)$ & {$[44.25,105.31]$} & $(105.31,157.08]$ & $(157.08,232.74]$ & $(232.74,694.69]$ \\
\hline Spearman $\mathrm{R}$ ( $P$ value) & $-0.021(0.871)$ & $0.106(0.370)$ & $0.200(0.085)$ & $0.549\left(<0.001^{*}\right)$ \\
\hline Slope & $0.01 \pm 0.12$ & $0.21 \pm 0.12$ & $0.19 \pm 0.11$ & $0.81 \pm 0.17$ \\
\hline Intercept & $16.01 \pm 1.68$ & $14.59 \pm 2.53$ & $18.24 \pm 2.88$ & $2.98 \pm 6.70$ \\
\hline
\end{tabular}

All statistics means incorporating all data of fasting, $2 \mathrm{~h}$ postprandial and $4 \mathrm{~h}$ postprandial $\mathrm{RCe}, \mathrm{RCn}$ and TGe into statistical analysis *Indicates statistical significance $P<0.05$

compared the within-subject differences between RCe and $\mathrm{RCn}[(\mathrm{RCe}-\mathrm{RCn}) / \mathrm{RCn})]$ in the TGe-low and TGehigh group. Except for the $4 \mathrm{~h}$ postprandial state, regardless of the presence or absence of CAD, significant differences were found in (RCe- $\mathrm{RCn}) / \mathrm{RCn}$ between the two groups (Fig. 4 and Additional File 1: Table S2). Moreover, this study incorporated all data of fasting, $2 \mathrm{~h}$ postprandial, and $4 \mathrm{~h}$ postprandial $\mathrm{RCe}, \mathrm{RCn}$, and TGe into the statistical analysis. As demonstrated in Fig. 5, the RCe levels were nearly close to the $\mathrm{RCn}$ levels across the 2nd and 3rd quartiles. Besides, the RCe levels tended to overestimate the RCn levels in the 1st quartile of the TGe levels with median differences of $0.23(-0.13,0.63)$ and to underestimate $\mathrm{RCn}$ levels with median differences of $-0.23(-0.33,0.07)$ in the highest quartile of the TGe levels.

Furthermore, logistic regression analysis was performed to assess the association between CAD and different assessments of RC. As shown in Additional File 1: Table S3, $2 \mathrm{~h}$ postprandial RCe (OR 1.54; 95\% CI 1.12-2.12) and fasting RCn (OR 1.64; 95\% CI 1.01-2.67) independently predicted CAD.

\section{Discussion}

Up to now, this study is the first to compare RC measured by NMR (RCn) with RC calculated from the standard lipid profile using the eq. TC - LDL-C - HDL$\mathrm{C}$ (RCe). Although notable discrepancies exist between $\mathrm{RCe}$ and $\mathrm{RCn}$, the results showed that both $\mathrm{RCe}$ and $\mathrm{RCn}$ levels are significantly elevated after a meal in CAD and non-CAD participants. This study also highlights that RCe could overestimate or underestimate RCn according to different TG levels.

As shown in this study, RCe levels were not equal to $R C n$ levels, but both of them increased after a meal. After a daily meal, CM and CM-Rs which are produced from the intestine appear in the bloodstream and reach the peak at $4 \mathrm{~h}$ postprandial $[35,36]$. As a result of the increased liver synthesis and CMs competing for the same lipolytic pathway, levels of large VLDL also increase after a meal [37]. In this study, the RC levels at three time points including fasting, $2 \mathrm{~h}$ postprandial, and $4 \mathrm{~h}$ postprandial states were obtained. Similar to the TG levels, both RCe and RCn levels showed an upward trend lasting at least $4 \mathrm{~h}$ after a typical breakfast in $\mathrm{CAD}$ and non-CAD participants, except for the slight decrease in RCn levels in CAD patients. Although the phenomenon that $\mathrm{RC}$ levels increased after meals has been observed in previous studies [34, 38], the study participants were encouraged to choose their breakfast according to their dietary habits, so the results were closer to real situations. Although RC always has a great correlation with the risk of incident $C A D$, irrespective of the fasting or nonfasting state $[3,8,11]$, the human body is in a non-fasting state most of the day. Therefore, compared with fasting RC levels, postprandial RC levels are more valuable for cardiovascular risk assessment.

Although using an estimate derived from a standard lipid profile to study RC is a convenient and intuitive approach, this method has limitations. This study used NMR-measured RCn and compared it with calculated 


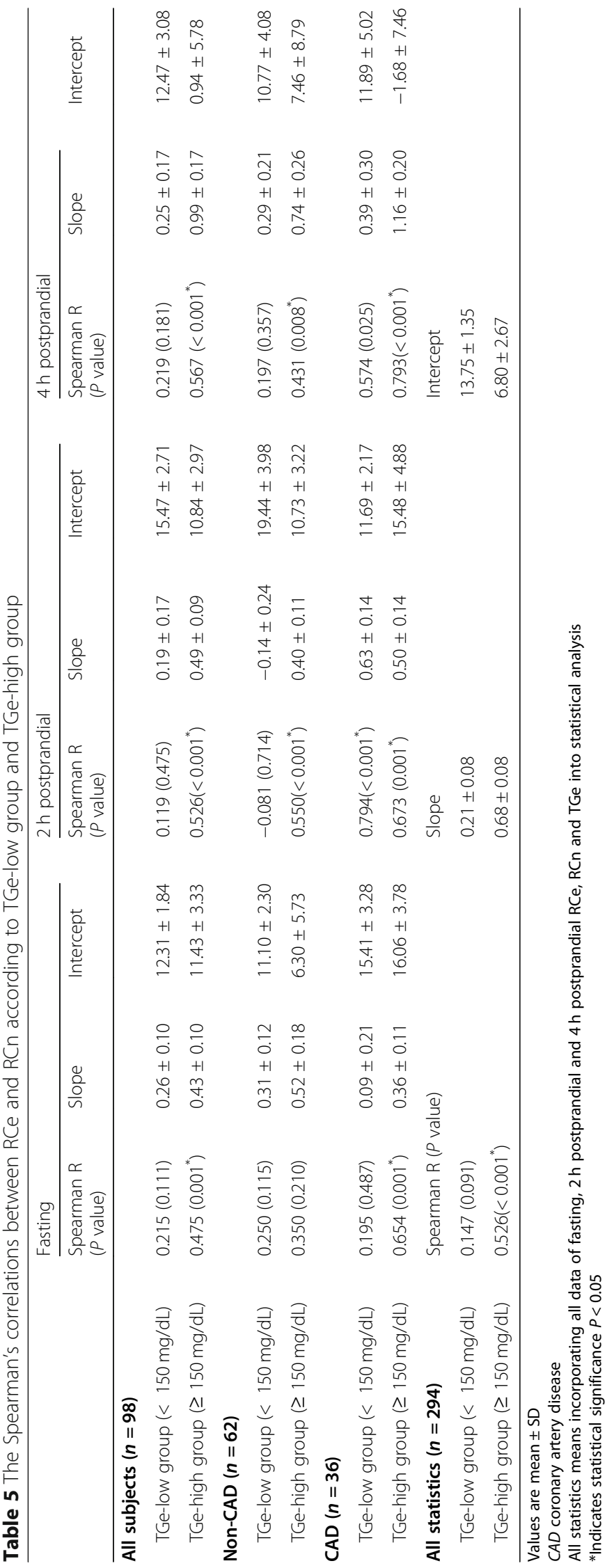




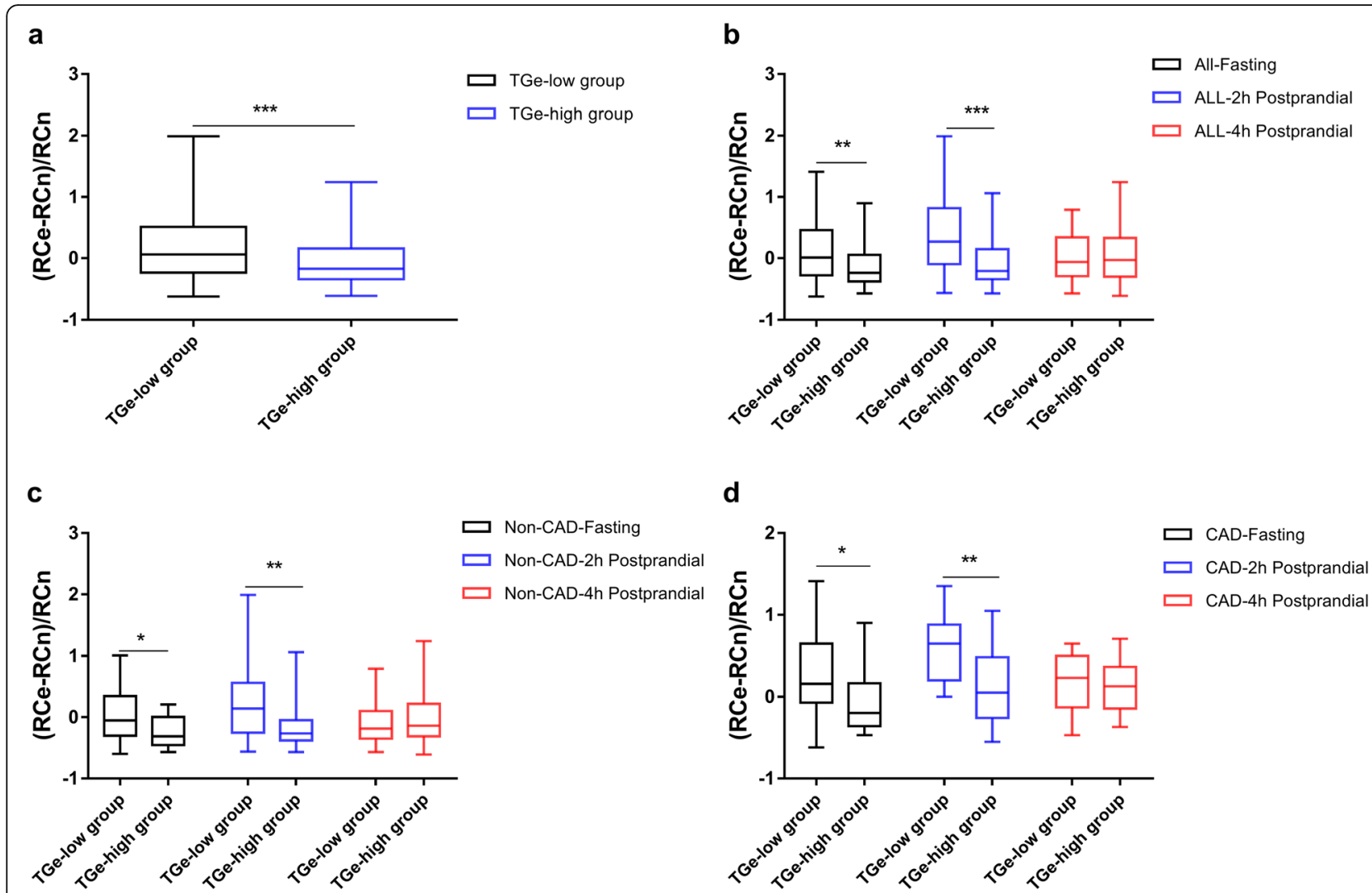

Fig. 4 Comparisons between RCe and RCn in different groups at different time points. TGe-low group: < $150 \mathrm{mg} / \mathrm{dL} ;$ TGe-high group: $\geq 150 \mathrm{mg} /$ dL. (a) Incorporating all data of fasting, $2 \mathrm{~h}$ postprandial and $4 \mathrm{~h}$ postprandial RCe, RCn and TGe into statistical analysis; (b) in all subjects; (c) in non-CAD group; (d) in CAD group. ** means $P$ value $<0.001$; ** means $P$ value $<0.01$; ${ }^{*}$ means $P$ value $<0.05$

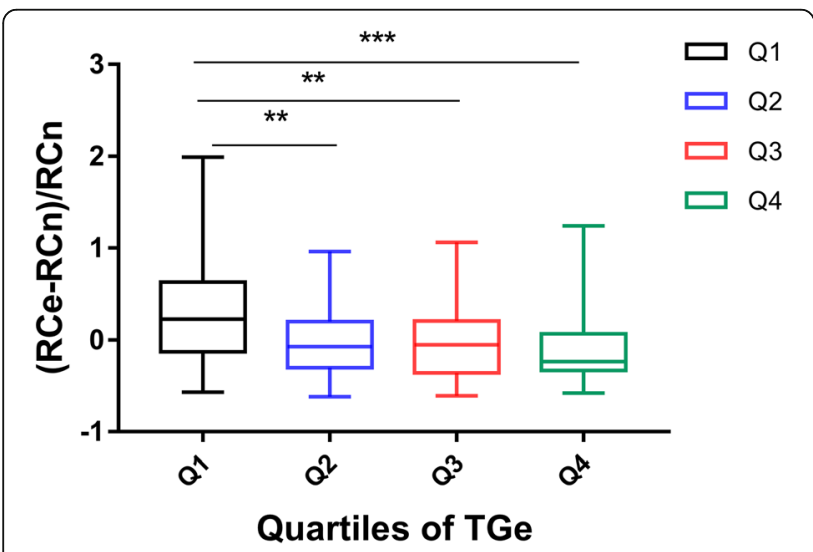

Fig. 5 Comparisons between RCe and RCn at different TG levels in all subjects.(A) Incorporating all data of fasting, $2 \mathrm{~h}$ postprandial and $4 \mathrm{~h}$ postprandial RCe, RCn and TGe into statistical analysis, comparison between RCe and RCn in all quartiles of TGe, Q1: TGe $\leq 105.31 \mathrm{mg} / \mathrm{dL}$, $\mathrm{Q} 2: \mathrm{TGe}=105.32-157.08 \mathrm{mg} / \mathrm{dL} ; \mathrm{Q} 3: \mathrm{TGe}=157.09-232.74 \mathrm{mg} / \mathrm{dL} ; \mathrm{Q} 4:$ TGe $>232.74 \mathrm{mg} / \mathrm{dL}$; ${ }^{* *}$ means $P$ value $<0.001 ;{ }^{* *}$ means $P$ value $<0.01$
RCe. Limited positive correlations between $\mathrm{RCn}$ and RCe were observed $(\mathrm{R}=0.586,0.534$, and 0.653 for fasting, $2 \mathrm{~h}$, and $4 \mathrm{~h}$, respectively), which represent only half the variance with RCe. A previous study has also shown that RCe cannot reflect the true RC [7]. There are two main reasons for the discrepancies between $\mathrm{RCe}$ and RCn. First, Friedewald-estimated LDL-C or LDL-Ce includes IDL-C and is excluded from the $\mathrm{RC}$ calculated from the standard lipid profile [8, 9, 39]. Furthermore, the sum levels of LDL-Cn and IDL-C were smaller than the LDL-Ce levels in the fasting and $2 \mathrm{~h}$ postprandial states. This is because in addition to IDL-C, LDL-Ce also includes cholesterol in other lipoproteins, which is perhaps lipoprotein (a) $[\operatorname{lp}(a)][8,9]$. Second, remnant size is important for atherogenicity. CMs and large VLDL are too large and cannot enter the arterial wall and probably do not cause atherosclerosis [40, 41]. However, small-to-medium-sized VLDL and CM-Rs are small enough to enter the arterial wall, but are too large to completely return to the bloodstream and thus are trapped inside the arterial wall [42-44]. Actually, RCe is the cholesterol cluster of all TG-rich lipoproteins, which include VLDLs, VLDL-Rs, IDLs, CMs, and CM-Rs. Unlike $\mathrm{RCe}, \mathrm{RCn}$ is defined as the sum of the cholesterol 
contents of the densest VLDL-C subfraction and IDL-C measured by NMR, which is probably best used for smaller TG-rich lipoprotein particles that cause atherosclerosis. Unfortunately, so far, no studies compared the ability of $\mathrm{RCe}$ and $\mathrm{RCn}$ in predicting CAD risk. This study does not show that $\mathrm{RCn}$ has a stronger ability to predict $\mathrm{CAD}$ than $\mathrm{RCe}$, which may be related to the small sample size. Further research with larger cohort is needed to address this issue.

Although calculated RC and NMR-measured RC are different, the results of this study suggest that the relationship between $\mathrm{RCe}$ and $\mathrm{RCn}$ is related to TG levels. Then, when their correlations stratified by TG quartiles were analyzed, it was found that the higher TG levels, the stronger correlation between RCe and RCn. Moreover, this study explored the correlations between RCe and RCn hierarchized by abnormal TG levels $(150 \mathrm{mg} /$ $\mathrm{dL}$ ) at fasting state in clinic and found that RCe had low correlations with RCn when the TG levels were $<150$ $\mathrm{mg} / \mathrm{dL}$. However, RCe showed positive correlations with $\mathrm{RCn}$ at high TG levels $(\geq 150 \mathrm{mg} / \mathrm{dL}, \mathrm{R}>0.5)$. When the absolute values of $\mathrm{RCe}$ and $\mathrm{RCn}$ were compared, although a substantial discordance between RCe and $\mathrm{RCn}$ is further demonstrated, RCe levels are nearly equal to RCn levels within certain TG levels. These findings imply that using calculated RC instead of direct measurements to evaluate actual $\mathrm{RC}$ in research studies or clinical practice may be feasible. However, a larger sample study is needed to explore the relationship between their absolute values and find the cutoff value of TG.

\section{Study strengths and limitations}

The present study has a number of strengths. This was the first study to explore differences and relationships between calculated RC and NMR-measured RC. The findings that RCe levels are nearly equal to RCn levels within certain TG levels proposed the clinical applicability of calculated RC. Besides, this study analyzed the results based on participants under daily life conditions which would provide more universal and generalizable results. Another strength of this study was the division of non-fasting state into $2 \mathrm{~h}$ and $4 \mathrm{~h}$ after a meal which was more detailed than previous studies. However, these findings should be interpreted in the context of several potential limitations. First, it is impossible to solely differentiate CM-Rs using the NMR spectroscopy method. Second, although a consensus method of measuring remnant lipoprotein levels is not established, numerous clinical studies have widely demonstrated that high $\mathrm{RCe}$ levels are a significant independent risk for ASCVD. Studies comparing RCs measured using other available methods are needed to determine additional discordance for further studies. Relevant studies are also needed to evaluate the association between different assessments of
RC and ASCVD more accurately. In addition, the sample size is small and a further research in larger cohort is needed.

\section{Conclusions}

In this study, both RCe and RCn levels were increased after a meal. These results imply that testing postprandial RC especially at $4 \mathrm{~h}$ to predict ASCVD risk is meaningful. Notable discrepancies exist between RCe and $\mathrm{RCn}$, and RCe could overestimate or underestimate $\mathrm{RCn}$ according to different TG levels. Thus, it is necessary to develop a consensus clinical method for measuring RC levels, so that results from different studies and platforms can be compared more directly. This would be an important step in the study of RC, which might serve as a potential target for therapy in the future. Moreover, the phenomenon that RCe levels are nearly equal to RCn levels within certain TG levels imply that using calculated RC, which is a simple and convenient method of evaluating actual $\mathrm{RC}$ instead of direct measurements in research studies or clinical practice, may be feasible. However, a further research in larger sample is needed to find the TG cutoff value.

\section{Supplementary information}

Supplementary information accompanies this paper at https://doi.org/10. 1186/s12944-020-01311-w.

Additional file 1: Table S1. Experimental Parameters. Table S2. Values of (RCe-RCn)/RCn at fasting, $2 \mathrm{~h}$ and $4 \mathrm{~h}$ postprandial states according to TGe-low group and TGe-high group. Table S3. Logistic regression analysis for the association of RCe and RCn with CAD in fasting and nonfasting states $(n=98)$

\section{Abbreviations}

ASCVD: Atherosclerotic cardiovascular disease; CAD: Coronary artery disease; CM-Rs: Chylomicron remnants; CMs: Chylomicrons; HDL-C: High-density lipoprotein cholesterol; IDL-C: Intermediate-density lipoprotein cholesterol; IDLs: Intermediate-density lipoproteins; LDL-C: Low-density lipoprotein cholesterol; NMR: Nuclear magnetic resonance; RC: Remnant cholesterol RC; RLs: Remnant lipoproteins; TC: Total cholesterol; TG: Triglyceride; VLDL ${ }_{3}$ C: Subfraction 3 of very low-density lipoprotein cholesterol; $V_{L D L_{4}}$ C: Subfraction 4 of very low-density lipoprotein cholesterol; $\mathrm{VLDL}_{5}{ }^{-}$ C: Subfraction 5 of very low-density lipoprotein cholesterol; VLDL-Rs: VLDL remnants

\section{Acknowledgments}

All authors are grateful to the National Natural Science Foundation of China, Natural Science Foundation of Hunan Province of China, and XinXin Heart (SIP) Foundation of China for their financial support. The authors also appreciate the nursing staff of the Department of Cardiovascular Medicine of the Second Xiangya Hospital for their support.

\section{Authors' contributions}

Bilian Yu made contributions to the conception and design of the study. Jin Chen analyzed the data, wrote the manuscript and drew the figures; Jie Kuang also analyzed some data and wrote some part of manuscript; Ling Mao collected blood samples; Xiaoyu Tang conducted the experiments; Xin Guo and Qin Luo collected the information of the subjects. Daoquan Peng provided suggestions for the study. All the authors have accepted responsibility for the entire content of this submitted manuscript and approved submission. 


\section{Funding}

This work was supported by the National Natural Science Foundation of China [No: 81170260 to Yu B]; Natural Science Foundation of Hunan Province of China [No: 2018JJ1045 to Yu B]; XinXin Heart (SIP) Foundation, China [No: 2019-CCA-ACCESS-028 to Yu B].

\section{Availability of data and materials}

The datasets used and/or analysed during the current study are available from the corresponding author on reasonable request.

\section{Ethics approval and consent to participate}

The study was approved by the Medical Ethics Committee of the Second Xiangya Hospital of Central South University, and the trial was registered at Chinese Clinical Trial Registry as ChiCTR1900020873. Informed consents were gained from all subjects.

\section{Consent for publication}

Not applicable.

\section{Competing interests}

The authors declare that they have no competing interests.

Received: 6 April 2020 Accepted: 4 June 2020

Published online: 10 June 2020

\section{References}

1. Timmis A, Townsend N, Gale CP, Torbica A, Lettino M, Petersen SE, Mossialos EA, Maggioni AP, Kazakiewicz D, May HT, et al. European Society of Cardiology: Cardiovascular Disease Statistics 2019 (executive summary). 2020Eur Heart J. Quality of care \& clinical outcomes. 6(1):7-9.

2. Yang G, Wang $Y$, Zeng $Y$, Gao GF, Liang X, Zhou M, Wan X, Yu S, Jiang Y, Naghavi M, et al. Rapid health transition in China, 1990-2010: findings from the global burden of disease study 2010. Lancet. 2013;381(9882):1987-2015.

3. Elshazly MB, Mani P, Nissen S, Brennan DM, Clark DI, Martin S, Jones SR, Quispe R, Donnellan E, Nicholls SJ, et al. Remnant cholesterol, coronary atheroma progression and clinical events in statin-treated patients with coronary artery disease [published online ahead of print, 2019 Nov 19]. Eur J Prev Cardiol. 2019;2047487319887578.

4. Lin A, Nerlekar N, Rajagopalan A, Yuvaraj J, Modi R, Mirzaee S, Munnur RK, Seckington M, Doery JCG, Seneviratne S, et al. Remnant cholesterol and coronary atherosclerotic plaque burden assessed by computed tomography coronary angiography. Atherosclerosis. 2019;284:24-30.

5. Joshi PH, Martin SS, Blumenthal RS. The remnants of residual risk. J Am Coll Cardiol. 2015;65(21):2276-8.

6. Nordestgaard BG. A test in context: lipid profile, fasting versus nonfasting. J Am Coll Cardiol. 2017;70(13):1637-46.

7. Faridi KF, Quispe R, Martin SS, Hendrani AD, Joshi PH, Brinton EA, Cruz DE, Banach M, Toth PP, Kulkarni K, et al. Comparing different assessments of remnant lipoprotein cholesterol: the very large database of lipids. J Clin Lipidol. 2019;13(4):634-44.

8. Joshi PH, Khokhar AA, Massaro JM, Lirette ST, Griswold ME, Martin SS, Blaha MJ, Kulkarni KR, Correa A, D'Agostino RB, et al. Remnant Lipoprotein Cholesterol and Incident Coronary Heart Disease: The Jackson Heart and Framingham Offspring Cohort Studies. J Am Heart Assoc. 2016;5(5):e002765.

9. Balling M, Langsted A, Afzal S, Varbo A, Smith GD, Nordestgaard BG. A third of nonfasting plasma cholesterol is in remnant lipoproteins: lipoprotein subclass profiling in 9293 individuals. Atherosclerosis. 2019;286:97-104.

10. Varbo A, Benn M, Tybjaerg-Hansen A, Nordestgaard BG. Elevated remnant cholesterol causes both low-grade inflammation and ischemic heart disease, whereas elevated low-density lipoprotein cholesterol causes ischemic heart disease without inflammation. Circulation. 2013;128(12): 1298-309.

11. Varbo A, Benn M, Tybjaerg-Hansen A, Jorgensen AB, Frikke-Schmidt R, Nordestgaard BG. Remnant cholesterol as a causal risk factor for ischemic heart disease (vol 61, pg 427, 2013). J Am Coll Cardiol. 2019;73(8):987-8.

12. Varbo A, Nordestgaard BG. Remnant cholesterol and risk of ischemic stroke in 112,512 individuals from the general population. Ann Neurol. 2019;85(4):550-9.

13. Anonymous. Evaluation of serum lipoprotein and cholesterol measurements as predictors of clinical complications of atherosclerosis; report of a cooperative study of lipoproteins and atherosclerosis. Circulation. 1956;14(4 Part 2):691-742.

14. Sandesara PB, Virani SS, Fazio S, Shapiro MD. The forgotten lipids: triglycerides, remnant cholesterol, and atherosclerotic cardiovascular disease risk. Endocr Rev. 2019;40(2):537-57.

15. Grundy SM, Vega GL, Tomassini JE, Tershakovec AM. Comparisons of Apolipoprotein B levels estimated by immunoassay, nuclear magnetic resonance, vertical auto profile, and non-high-density lipoprotein cholesterol in subjects with hypertriglyceridemia (SAFARI trial). Am J Cardiol 2011;108(1):40-6.

16. Pagnan A, Havel RJ, Kane JP, Kotite L. Characterization of human very low density lipoproteins containing two electrophoretic populations: double pre-beta lipoproteinemia and primary dysbetalipoproteinemia. J Lipid Res. 1977;18(5):613-22.

17. Nakamura T, Kugiyama K. Triglycerides and remnant particles as risk factors for coronary artery disease. Curr Atheroscler Rep. 2006;8(2):107-10.

18. Leary ET, Wang T, Baker DJ, Cilla DD, Zhong J, Warnick GR, Nakajima K, Havel RJ. Evaluation of an immunoseparation method for quantitative measurement of remnant-like particle-cholesterol in serum and plasma. Clin Chem. 1998:44(12):2490-8.

19. Varbo A, Nordestgaard BG. Remnant lipoproteins. Curr Opin Lipidol. 2017; 28(4):300-7.

20. Hermans MP, Ahn SA, Rousseau MF. Novel unbiased equations to calculate triglyceride-rich lipoprotein cholesterol from routine non-fasting lipids. Cardiovasc Diabetol. 2014;13(1):56.

21. Otvos JD, Jeyarajah EJ, Bennett DW. Quantification of plasma lipoproteins by proton nuclear magnetic resonance spectroscopy. Clin Chem. 1991;37(3): 377-86.

22. Arsenault BJ, Lemieux I, Despres J, Wareham NJ, Stroes ESG, Kastelein JJP, Khaw K, Boekholdt SM. Comparison between gradient gel electrophoresis and nuclear magnetic resonance spectroscopy in estimating coronary heart disease risk associated with LDL and HDL particle size. Clin Chem. 2010; 56(5):789-98.

23. Tsai MY, Georgopoulos A, Otvos JD, Ordovas JM, Hanson NQ, Peacock JM, Arnett DK. Comparison of ultracentrifugation and nuclear magnetic resonance spectroscopy in the quantification of triglyceride-rich lipoproteins after an oral fat load. Clin Chem. 2004;50(7):1201-4.

24. PC M, Nitin S, HJ R, PI J. Dietary Inflammatory Index and Biomarkers of Lipoprotein Metabolism, Inflammation and Glucose Homeostasis in Adults. Nutrients. 2018;10(8):1033.

25. Kettunen J, Holmes MV, Allara E, Anufrieva O, Ohukainen P, Oliver-Williams C, Wang Q, Tillin T, Hughes AD, Kahonen M, et al. Lipoprotein signatures of cholesteryl ester transfer protein and HMG-CoA reductase inhibition. PLoS Biol. 2019;17(12):e3000572.

26. Llaurado G, Amigo N, Cano A, Ballesta S, Albert L, Mazarico I, FernandezVeledo S, Pedro-Botet J, Vendrell J, Gonzalez-Clemente J. Specific Nuclear Magnetic Resonance Lipoprotein Subclass Profiles and Central Arterial Stiffness in Type 1 Diabetes Mellitus: A Case Control Study. J Clin Med. 2019; 8(11):1875.

27. Zhang T, Tang X, Mao L, Chen J, Kuang J, Guo X, Xu D, Peng D, Yu B. HDLassociated apoCIII plays an independent role in predicting postprandial hypertriglyceridemia. Clin Biochem. 2020;79:14-22.

28. Jimenez B, Holmes E, Heude C, Tolson RF, Harvey N, Lodge SL, Chetwynd AJ, Cannet C, Fang F, Pearce JTM, et al. Quantitative lipoprotein subclass and low molecular weight metabolite analysis in human serum and plasma by H-1 NMR spectroscopy in a multilaboratory trial. Anal Chem. 2018;90(20): 11962-71.

29. Wider G, Dreier L. Measuring protein concentrations by NMR spectroscopy. J Am Chem Soc. 2006;128(8):2571-6.

30. Harbaum L, Ghataorhe P, Wharton J, Jimenez B, Howard LSG, Gibbs JSR, Nicholson JK, Rhodes CJ, Wilkins MR. Reduced plasma levels of small HDL particles transporting fibrinolytic proteins in pulmonary arterial hypertension. Thorax. 2019;74(4):380-9.

31. Okazaki M, Usui S, Ishigami M, Sakai N, Nakamura T, Matsuzawa Y, Yamashita S. Identification of unique lipoprotein subclasses for visceral obesity by component analysis of cholesterol profile in high-performance liquid chromatography. Arterioscl Throm Vas. 2005;25(3):578-84.

32. Mannisto $V T$, Simonen $M$, Soininen $P$, Tiainen $M$, Kangas AJ, Kaminska D, Venesmaa S, Kakela P, Karja V, Gylling H, et al. Lipoprotein subclass metabolism in nonalcoholic steatohepatitis. J Lipid Res. 2014;55(12): 2676-84. 
33. Wang T, Nakajima K, Leary ET, Warnick GR, Cohn JS, Hopkins PN, Wu LL, Cilla DD, Zhong JH, Havel RJ. Ratio of remnant-like particle-cholesterol to serum total triglycerides is an effective alternative to ultracentrifugal and electrophoretic methods in the diagnosis of familial type III hyperlipoproteinemia. Clin Chem. 1999;45(11):1981-7.

34. NB G, Anne L, Samia M, Genovefa K, Hannsjörg B, Eric B, WG F, Grazyna S, Olov W, Jan B, et al. Fasting is not routinely required for determination of a lipid profile: clinical and laboratory implications including flagging at desirable concentration cut-points-a joint consensus statement from the European Atherosclerosis Society and European Federation of Clinical Chemistry and Laboratory Medicine. Eur Heart J. 2016;37(25):1944-58.

35. Weintraub MS, Grosskopf I, Rassin T, Miller H, Charach G, Rotmensch HH, Liron M, Rubinstein A, laina A. Clearance of chylomicron remnants in normolipidaemic patients with coronary artery disease: case control study over three years. BMJ (Clinical Res ed). 1996;312(7036):935-9.

36. Chernova DN, Konokhova Al, Novikova OA, Yurkin MA, Strokotov DI, Karpenko AA, Chernyshev AV, Maltsev VP. Chylomicrons against light scattering: The battle for characterization. J Biophotonics. 2018;11(10): e201700381.

37. Karpe F, Hellenius ML, Hamsten A. Differences in postprandial concentrations of very-low-density lipoprotein and chylomicron remnants between normotriglyceridemic and hypertriglyceridemic men with and without coronary heart disease. Metabolism. 1999;48(3):301-7.

38. Park C, Park J, Choi J, Kim DJ, Park KS, Yoon K, Lee M, Park S. Increased postprandial apolipoprotein B-48 level after a test meal in diabetic patients: a multicenter, cross-sectional study. Metabolism. 2016;65(6):843-51.

39. Senti M, Pedro-Botet J, Nogues X, Rubies-Prat J. Influence of intermediatedensity lipoproteins on the accuracy of the Friedewald formula. Clin Chem. 1991;37(8):1394-7.

40. Nordestgaard BG, Zilversmit DB. Large lipoproteins are excluded from the arterial wall in diabetic cholesterol-fed rabbits. J Lipid Res. 1988; 29(11):1491-500.

41. Nordestgaard BG, Stender S, Kjeldsen K. Reduced atherogenesis in cholesterol-fed diabetic rabbits. Giant lipoproteins do not enter the arterial wall. Arteriosclerosis (Dallas, Tex.). 1988;8(4):421-8.

42. Shaikh M, Wootton R, Nordestgaard BG, Baskerville P, Lumley JS, La Ville AE, Quiney J, Lewis B. Quantitative studies of transfer in vivo of low density, Sf 12-60, and Sf 60-400 lipoproteins between plasma and arterial intima in humans. Arterioscler Thromb. 1991;11(3):569-77.

43. Nordestgaard BG, Wootton R, Lewis B. Selective retention of VLDL, IDL, and $L D L$ in the arterial intima of genetically hyperlipidemic rabbits in vivo. Molecular size as a determinant of fractional loss from the intima-inner media. Arterioscler Thromb Vasc Biol. 1995;15(4):534-42.

44. Nordestgaard BG. Triglyceride-rich lipoproteins and atherosclerotic cardiovascular disease new insights from epidemiology, genetics, and biology. Circ Res. 2016;118(4):547-63.

\section{Publisher's Note}

Springer Nature remains neutral with regard to jurisdictional claims in published maps and institutional affiliations.

Ready to submit your research? Choose BMC and benefit from:

- fast, convenient online submission

- thorough peer review by experienced researchers in your field

- rapid publication on acceptance

- support for research data, including large and complex data types

- gold Open Access which fosters wider collaboration and increased citations

- maximum visibility for your research: over $100 \mathrm{M}$ website views per year

At $\mathrm{BMC}$, research is always in progress.

Learn more biomedcentral.com/submissions 